\section{Snow: reflections on physics in our time}

\author{
H.B.G. Casimir
}

The Physicists: A Generation that Changed the World. By C.P. Snow. Pp.192. ISBN UK 0-333-3228-2; ISBN US 0-316-80221-2. (Macmillan, London/ Little, Brown: 1981.) £8.95, \$15.95.

Although physicists like to insist that they are anything but narrow-minded specialists, only few of us have been professionally successful outside the field of science. C.P. Snow was one such rara avis. After an honourable career at Cambridge as a research fellow and later as a tutor at Christ's College, he became famous as a novelist and, moreover, distinguished himself as a Civil Service Commissioner. In his well-known Rede Lecture of 1959 he stressed the gap between "Two Cultures"' but he himself tried to bridge that gap - his novels have given many readers a better understanding of the attitudes and aspirations of academic scientists.

In the present book, the first draft of which was completed just before his death on 1 July 1980, Lord Snow returns to science. In eleven chapters he depicts in broad strokes the stupendous development of physics during our century, tells about the main contributors to that development, explains its decisive influence on human society and dwells on the moral responsibility of scientists. In addition there are three appendices: Snow's farsighted editorial in Discovery of September
1939; Einstein's letter to President Roosevelt; and Snow's speech on the moral un-neutrality of science, delivered in 1960 to the American Association for the Advancement of Science. The book is abundantly illustrated with well chosen photographs and diagrams.

Most physicists will agree with the general tenor and with the message of Snow's book. Also, as was to be expected, Snow writes clearly and fluently, and he often succeeds in characterizing a physicist in a few pregnant sentences, for instance Fermi on p.79:

He had been recognized very young as one of the physicists of the century, and the only one who could work on equal terms with the greatest in both theory and experiment. There had been no one like that for generations . . . . If Fermi had been born thirty years earlier, it was possible to imagine him discovering Rutherford's nucleus, and then proceeding to Bohr's theory of the atom. . . . As a professional scientist, not as a cosmic thinker such as Einstein or Bohr, he was one of the very greatest.

William Cooper tells us in his introduction that Snow intended to write mainly from memory and it is clear that the book is not based on careful historical studies. It is a personal narrative, but a personal narrative by a man like Snow is well worth reading. For a physicist it is stimulating to compare Snow's choice and evaluation - often based on close acquaintance with the persons and the

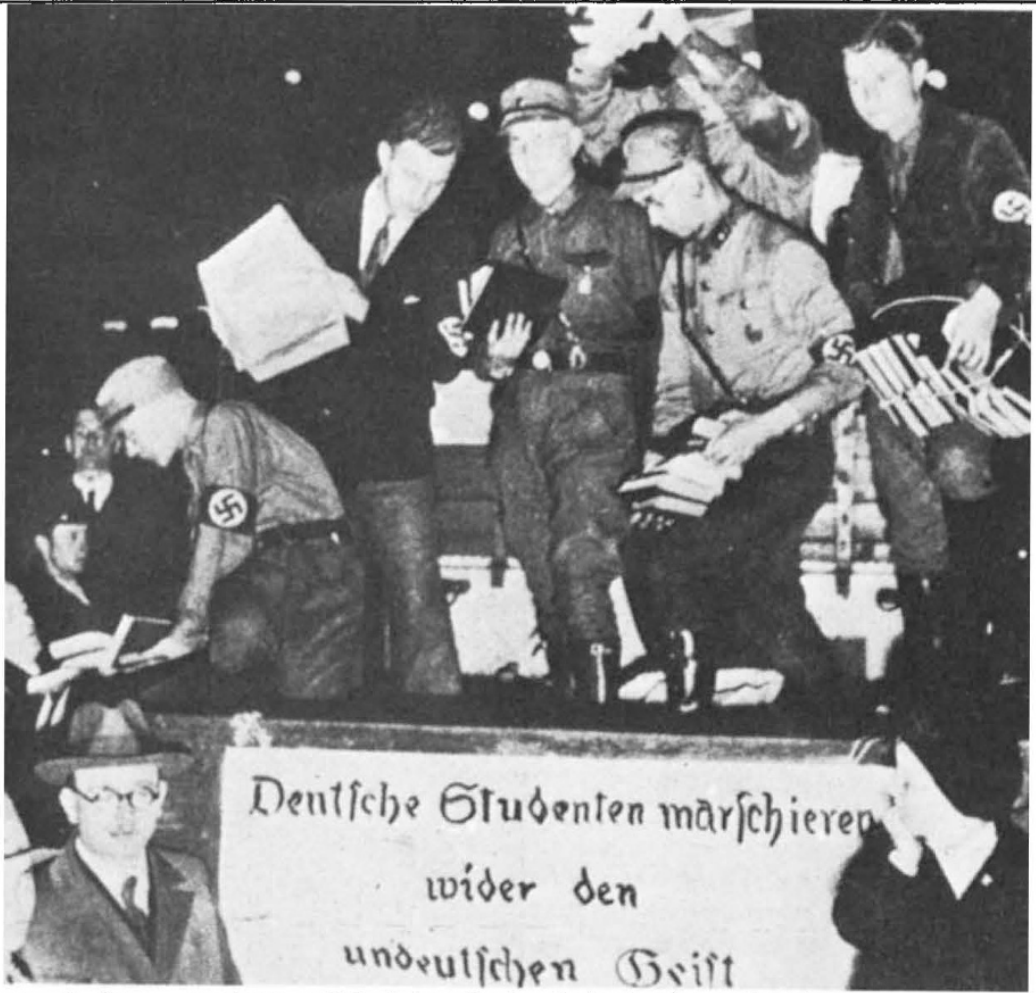

Germany in 1933 - students and Nazis burning books by foreign and Jewish authors. The slogan reads "German students march against the un-German intellect"'. Such scenes led to the flight of Jewish physicists from Germany and eventually to the development of the atomic bomb in the United States. subjects discussed - with one's own views. But a general reader should realize that Snow's presentation is often incomplete and may lead to a one-sided or even distorted picture: it is an interesting but not entirely reliable guide.

There is, for instance, no indication of the important role of kinetic theory and statistical mechanics in the development of the atomic theory of matter; Boltzmann is not mentioned, Gibbs only as the creator of chemical thermodynamics. Einstein's work in this field passes unnoticed also. Yet it was Perrin's experimental confirmation of Einstein's predictions concerning Brownian motion that convinced many unbelievers of the real existence of atoms. Similarly, Einstein's theory of the specific heat of solids at low temperatures convinced many physicists of the reality of quantization. When writing about crystallography and X-rays, Snow mentions W.L. Bragg (Sir Lawrence) and Bernal, but fails to mention Bragg's father (Sir William) and von Laue. Wave mechanics is called the De BroglieSchrödinger theory; that is fair, but note of the curious fact that both De Broglie and Schrödinger did not accept - or did so only with reluctance - Born's interpretation of the wave function as a probability amplitude should not have been omitted. Snow draws a lively picture of Feynman and sketches his work on quantum electrodynamics. Dyson is also mentioned, Schwinger and Tomonaga are not.

Sometimes the Cambridge (or more generally the British) point of view does not apply elsewhere. When Snow writes on p.42 "Until the Second World War there was little industrial support for physicists" this may have been true in England but in the United States, in Germany and also in my own country industry employed many physicists, some of them even Nobel Prize winners. Further, at Cambridge spectroscopy was considered to lie outside the main compass of physics. Elsewhere it was felt that Rutherford and his school were pioneering an as yet lonely track, whereas the main action was to be found in the unravelling of spectra, which indeed eventually led to the understanding of the periodic system, to the exclusion principle, to the notion of electronic spin and to the semi-quantitative vector model, thus paving the way for quantum mechanics. It was in the 1930s, after the birth of quantum mechanics, that nuclear physics burst into full bloom.

The book contains a number of plain errors, which Snow, had he lived, would presumably have corrected, and which a careful editor ought to have noticed. Uhlenbeck (p.113) was not involved in the mission of Goudsmit; the Göttingen Nobel Prize winner James Franck is turned into Josef (p. 117) and the index lists both James and the non-existent Josef; A.H. Compton was an American, not a British Nobel Laureate (p.120). It was not Gell-Mann- 
who introduced group theory into physics (p.145): that had been done by Wigner in the late 1920 s. Group theory then became one of the customary tools of theoretical physicists. Gell-Mann applied it ingeniously and successfully to the problems of particle physics.

In two cases Snow's tendency to sum up people in a few sentences leads to injustice. On p.112 he states bluntly that "General Groves was a singularly bad choice for his job". I have no well-founded personal opinion, but I notice that A.H. Compton writes in his Atomic Quest - by a curious coincidence also on p.112 - "The nation was fortunate indeed in the selection of General Groves for this task". Also, it cannot be denied that Groves's short-term mission was efficiently accomplished. The second case is worse. On p.26 Snow writes

. . L Lenard who, incidentally, as an old man was one of the only two eminent German scientists who became active spokesmen for the Nazi faith. (The other was Werner Heisenberg, a great theoretician ....).

Such parenthetic calumny should not go uncorrected. Certainly, Heisenberg was a German patriot. He loved his country; the German language and German culture meant much to him (but in the early 1920s the Jugendbewegung to which he belonged was not a nationalistic group). We may regret that he let his love for his country prevail over his objections to the Nazis, we may wish that he had taken a firmer and more courageous stand against them. And I admit that on the one occasion I met him during the war he showed little

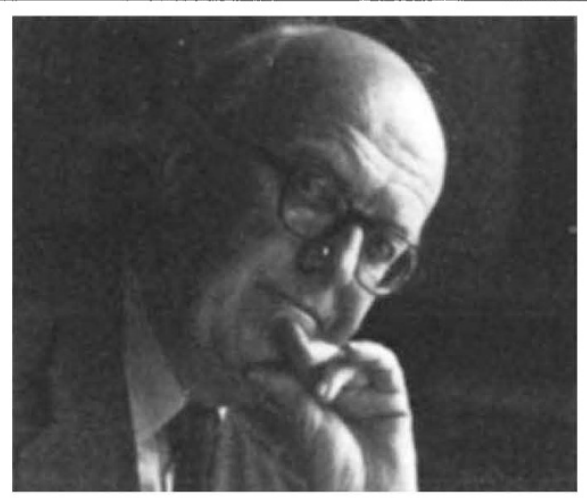

C.P. Snow 1905-1981

understanding for the feelings of people in an occupied country. But he always maintained his integrity as a physicist and at one time he was even under severe attack by members of the Lenard group, because he continued to express his belief in quantum theory and relativity. It is utterly wrong to mention him in one breath with Lenard.

Nevertheless, despite these detailed criticisms, I consider The Physicists a valuable book. Its theme is important, its basic structure sound and it contains many incisive remarks and interesting side-lights. I read it with pleasure and profit, and am convinced that many will do likewise.

H.B.G. Casimir studied theoretical physics at Leiden, Copenhagen and Zürich, worked in low temperature physics at Leiden and later joined the Philips Company at Eindhoven. He is a foreign member of the Royal Society and a former President of the European Physical Society.

\section{Philosophy in an uncertain world}

\section{John Polkinghorne}

Divine and Contingent Order. By Thomas F. Torrance. Pp.162. ISBN 0-19-826658-8. (Oxford University Press: 1981.) £9.50, $\$ 27.59$.

PROFESSOR Tom Torrance is a distinguished theologian, the chief apostle in this country of Karl Barth, whom many would regard as the most significant figure in twentieth-century theology. In addition, Torrance is one of the few British theologians to have taken a serious interest in what science has to say about the world. This reflects itself in Torrance's strongly objectivist approach to theology, and it is no accident that one of his best known books is called Theological Science.

His latest work is concerned with the assessment of the significance of the contingency that we find in nature. We can distinguish at least four senses in which such contingency is present: (i) The laws of nature are not necessary, in the sense that their form cannot be determined by pure thought alone but has to bc obtained from experimental observation. The recognition and exploitation of this is what gave modern science its superiority over that of the ancient world. (ii) The parameters appearing in those laws, such as the fine structure constant, take values which can only be determined empirically. Sir Arthur Eddington tried to deny this in Fundamental Theory and came to grief. However an interesting gloss on the values of these constants is provided by the anthropic principle which recognizes limitations to be satisfied in a universe in which we can emerge as observers. Torrance only mentions this in a footnote; it deserved greater consideration on his part. (iii) In the great diversity of things that happen there are unforeseeableconcatenations of circumstance. This is the "chance" that Monod saw operating in the emergence of life and which for him (but not for me) caused the fabric of significance to crumble. (iv) There is the radical unpredictability of quantum mechanical observation and (I would say) the action of the will, both topics which we do not understand very well.

It seems important to discriminate between these four aspects of contingence,
Bioscience Titles

\section{from}

\section{Pitman}

\section{NEW}

\section{Quantitative Ethology}

The State Space Approach

D McFarland and A Houston

The only systematic approach to the subject available, this is the first book to combine functional and mechanistic explanations of

behaviour at a quantitative level. It provides a theoretical framework for researchers to co-ordinate the numerous discoveries and examples that stem from the field of modern ecology.

ISBN 027308417 8/Cased/ $\$ 17.50$

Associated Animal Behaviour Title

The Social Biology of Ants K Dumpert

Provides a comprehensive review of the social and family life of ants in different and eco-ethological

conditions.

ISBN 027308479 8/£20

\section{NEW}

Pests, Pathogens and

Vegetation

The Role of Weeds and Wild Plants in the Ecology of Crop Pests and Diseases

Fdited by J M Thresh

A collection of forty pieces by different authors dealing with numerous aspects of the role of weeds and wild plants in the ecology of crop diseases. A strong underlying ecological theme gives continuity to this work, which should be of interest to a wide range of biologists.

ISBN 027308498 4/Cased/£30

Associated Applied Biology Title

\section{Opportunities for}

\section{Increasing Crop Yields}

Edited by Hurd, Biscoe and Dennis An important book discussing the most promising ways of achieving the maxiumum potential from different crops.

ISBN $027308481 \mathrm{X} /$ Cased/ $\$ 24$

Order from your bookseller, or use this advertisement as an order form: send it with your cheque/postal order to

CASHPOST SERVICE, BOOK CENTRE, SOUTHPORT PR9 9YF. If stocks are available, we guarantec to despatch your order within 48 hours.

Postage and Packing FREE. NAl $\% 11 / 81$

Pitman Books Limited, 39 Parker Street, London WC2B 5PB 